\title{
THE AGE OF PUBERTY IN LOCAL BREEDS OF CATTLE IN CENTRAL AFRICA
}

\author{
A. M. RAKHA, D. HALE* AND G. IGBOELI \\ Agricultural Research, National Council For Scientific Research, \\ P.O. Box 49, Chilanga, Lusaka
}

(Received 23rd December 1969)

The timing of puberty in relation to the life-span governs, in part, the total number of young produced and consequently the reproductive potential.

The object of the present study is to determine the age of puberty in the local breeds of cattle under the normal ranching conditions of Central Africa.

The experiment included eighteen Angoni, fifteen Africander, and twentythree Mashona heifers, and ten Hereford heifers for comparison, born in September, October and November 1967. Observations began when the animals were 9 months of age. The animals were weighed and their ovaries were palpated per rectum every fortnight. Dimensions of the ovaries, presence or absence of follicles and/or corpora lutea (cL) and changes in uterine size and texture were recorded. Oestrus was detected by young, raddled, vasectomized bulls, and animals were observed twice daily for oestrus.

Palpation of the ovaries revealed that, before the appearance of the first CL, there was a considerable fluctuation in the size of ovaries as a result of follicular growth and regression. The fate of these follicles is not clear.

TABLE 1

THE AGE AND WEIGHT OF CATTLE AT PUBERTY*

\begin{tabular}{l|c|c|c|c|c}
\hline \multirow{2}{*}{ Breed } & \multicolumn{2}{|c|}{ First corpus luteum } & \multicolumn{2}{c|}{ First oestrus } & $\begin{array}{c}\text { CL before } \\
\text { oestrust } \\
(\%)\end{array}$ \\
\cline { 2 - 3 } \cline { 5 - 6 } & Weight $(l b)$ & Age (days) & Weight $($ lb $)$ & Age (days) & \\
\hline Angoni & $428 \cdot 0 \pm 30 \cdot 2$ & $547 \cdot 7 \pm 23 \cdot 1$ & $425 \cdot 2 \pm 26 \cdot 9$ & $591 \cdot 2 \pm 17 \cdot 3$ & $61 \%$ \\
Mashona & $460 \cdot 0 \pm 29 \cdot 4$ & $571 \cdot 1 \pm 26 \cdot 8$ & $422 \cdot 0 \pm 20 \cdot 6$ & $596 \cdot 1 \pm 18 \cdot 0$ & $31 \%$ \\
Africander & $486 \cdot 9 \pm 45 \cdot 5$ & $557 \cdot 6 \pm 36 \cdot 1$ & $463 \cdot 0 \pm 43 \cdot 5$ & $573 \cdot 5 \pm 36 \cdot 2$ & $53 \%$ \\
Hereford & $556 \cdot 7 \pm 40 \cdot 1$ & $502 \cdot 0 \pm 16 \cdot 8$ & $591 \cdot 7 \pm 34 \cdot 8$ & $517 \cdot 6 \pm 14 \cdot 7$ & $80 \%$ \\
\hline
\end{tabular}

* Values expressed as mean \pm S.E.

$\dagger$ This represents the percentage of animals with CL before standing oestrus.

First oestrus (puberty) occurred at $591 \cdot 2 \pm 17 \cdot 3,596 \cdot 1 \pm 18 \cdot 0$, and $573 \cdot 5 \pm$ 36.2 days for the Angoni, Mashona and Africander breeds, respectively, whereas the first CL was observed approximately 1 to 2 months earlier. The Hereford heifers showed ovulation and oestrus at an earlier age but at a greater body weight.

* Present address: Department of Anatomy Medical School, University of Rhodesia, Salisbury. 
The age of puberty is regarded by some authors (Plasse, Warnick \& Koger, 1968) as the age when the first CL is observed, while others (Reynolds, De Rouen \& High, 1963; Wiltbank, Kasson \& Ingalls, 1969) regard it as the age at which a heifer first exhibits oestrus. Since receptivity is an important component of complete sexual function, the presence of a CL, not preceded by standing oestrus, cannot be regarded as the age of puberty. In addition, detectable oestrus is a more practical parameter. From the present results (Table 1), it seems that the presence of $\mathrm{CL}$ in more than $56 \%$ of animals before standing oestrus represents a necessary process. The occurrence of silent ovulation in sheep at the start of the breeding season underlines the importance of progesterone for the induction of behavioural oestrus (Robinson 1954; Robinson, Moore \& Binet, 1956). Although some heifers showed standing oestrus which was not preceded by silent ovulation, it is possible that these animals were hormonally primed from follicles which had undergone luteinization without ovulation or that ovulation may have taken place but the cu was small and undetectable. Further work is required to examine these possibilities.

There was a loss in body weight in all breeds during the period between the detection of the first cL and the occurrence of the first standing oestrus (Table 1) which is a normal feature at this season. The possible effect of this loss of weight on full sexual function cannot be ruled out. Further work is in progress to elucidate the factors affecting the age of puberty.

The authors are indebted to $\mathrm{Mr} \mathrm{J}$. Nguluwe for technical assistance.

\section{REFERENCES}

Plasse, D., Warnick, A. C. \& Koger, M. (1968) Reproductive behaviour of Bos indicus females in a subtropical environment. I. Puberty and ovulation frequency in Brahman and Brahman $x$ British heifers. F. Anim. Sci. 27, 94.

Reynolds, W. L., De Rouen, T. M. \& High, J. W., JR (1963) The age and weight at puberty of Angus, Brahman and Zebu cross heifers. F. Anim. Sci. 22, 243.

Robinson, T. J. (1954) The necessity for progesterone with estrogen for the induction of recurrent estrus in the ovariectomized ewe. Endocrinology, 55, 403.

Robinson, T. J., Moore, N. W. \& Binet, F. E. (1956) The effect of the duration of progesterone pretreatment on the response of the spayed ewe to estrogen. Endocrinology, 14, 1.

Wiltbank, J. N., Kasson, C. W. \& Ingalls, J. E. (1969) Puberty in crossbred and straightbred beef heifers on two levels of feed. 7. Anim. Sci. 29, 602. 